\title{
Relationship of vascular perfusion of the wall of the preovulatory follicle to in vitro fertilisation and embryo development in heifers
}

\author{
M A R Siddiqui ${ }^{1}$, E L Gastal ${ }^{2}$, M O Gastal ${ }^{1}, \mathrm{M} \mathrm{Almamun}^{1}$, M A Beg ${ }^{2}$ and O J Ginther ${ }^{1,2}$ \\ ${ }^{1}$ Eutheria Foundation, Cross Plains, Wisconsin 53528, USA and ${ }^{2}$ Department of Pathobiological Sciences, School of \\ Veterinary Medicine, University of Wisconsin-Madison, 1656 Linden Drive, Madison, Wisconsin 53706, USA
}

Correspondence should be addressed to O J Ginther; Email: ginther@svm.vetmed.wisc.edu

\begin{abstract}
The effect of the extent of vascular perfusion of the wall of the preovulatory follicle on in vitro cleavage rate of the recovered oocyte and embryo development to $>8$ cells was studied in 52 heifers. Heifers received a luteolytic dose of prostaglandin F2 $\alpha$ (PGF $2 \alpha)$ when the largest follicle was $\geq 11 \mathrm{~mm}$. An ovulation-inducing injection of $\mathrm{GnRH}$ was given $36 \mathrm{~h}$ later (hour 0 ), and collection of follicular fluid and the oocyte was done at hour 26. Vascular perfusion of the follicular wall was assessed by colour Doppler ultrasonography at hours 0 and 26. Each of the recovered oocytes $(41 / 52 ; 79 \%)$ was mature (extruded polar body). Cleavage and embryo development were assessed at $48 \mathrm{~h}$ and $120 \mathrm{~h}$ respectively, after in vitro fertilisation (IVF). The percentage of cleaved oocytes and $>8$ cell embryos was $80 \%(31 / 39)$ and $55 \%(17 / 31)$ respectively. Vascular perfusion of the follicular wall was greater (lower pulsatility index; $P<0.001)$ for follicles that produced cleaved versus non-cleaved oocytes and greater $(P<0.04)$ for follicles that produced $>8$ cell versus $\leq 8$ cell embryos.

Percentage of follicular wall with Doppler signals of blood flow was greater $(P<0.001)$ for $>8$ cell versus $\leq 8$ cell embryos. Follicularfluid concentration of free IGF1 was lower for cleaved oocytes $(P<0.001)$ and $>8$ cell embryos $(P<0.05)$, and oestradiol was lower $(P<0.05)$ for $>8$ cell embryos. Results supported the hypothesis that greater vascular perfusion of the wall of the preovulatory follicle was positively associated with IVF and embryo development.
\end{abstract}

Reproduction (2009) 137 689-697

\section{Introduction}

The use of colour Doppler ultrasonography for research and clinical studies of ovarian and follicular haemodynamics is increasing in women (Fleischer 1991) and large farm animals (Ginther \& Utt 2004, Miyamoto et al. 2006, Ginther 2007, Herzog \& Bollwein 2007). In women, several studies have indicated that the blood flow in the wall of the preovulatory follicle is an indication of the potential success of assisted reproductive techniques. Preovulatory examination of colour Doppler signals of blood flow in the follicular wall (Bhal et al. 2001) and vascular resistance distal to an intraovarian artery by spectral Doppler indices (Du et al. 2006) are useful for assessing the quality of the oocyte. Bhal et al. (2001) reported that follicle vascularity is a factor in determining the success of pregnancy establishment after intrauterine insemination. Greater blood flow in the wall of the preovulatory follicle also has been associated with improved rates of in vitro fertilisation (IVF) and embryo development (Bhal et al. 1999, Coulam et al. 1999, Huey et al. 1999, Du et al. 2006, Shrestha et al. 2006). These studies have indicated that colour Doppler ultrasonographic analysis of individual preovulatory follicles for collection of oocytes for IVF in women may favour selection of oocytes with better development and implantation potential of the embryos. In a few studies, a positive relationship was not found between follicular blood flow and pregnancy establishment after intrauterine insemination (Ragni et al. 2007) or after IVF-derived embryo transfer (Ng et al. 2006). However, these studies were complicated by variation in the infertility history of the women, the use of both conventional IVF and intracytoplasmic sperm injection, or the use of semen from different donors.

Follicular blood-flow assessment by colour Doppler ultrasonography has been used in mares after hCG treatment to study follicle vascularity in regard to maturity of the preovulatory follicle (Gastal et al. 2006) and the oocyte (Ginther et al. 2007), and oocyte quality in presence of circulating hCG antibodies (Siddiqui et al. 2009a). The vascularity tended to be greater for preovulatory follicles that contained a mature oocyte (Ginther et al. 2007). Mares that were negative for hCG antibodies had greater frequency of mature oocytes and greater vascularity of the follicular wall (Siddiqui et al. 
2009a). Colour Doppler assessment of blood flow in the follicular wall in mares (Silva et al. 2006) and heifers (Siddiqui et al. 2009b) indicated that follicular blood flow was greater in the animals that became pregnant after insemination.

In summary, greater vascularity of the preovulatory follicle has been associated with greater follicular diameter (women: Bhal et al. 1999, mares: Silva et al. 2006, heifers: Siddiqui et al. 2009b), retrieval rate of oocytes (women: Bhal et al. 1999, mares: Ginther et al. 2007), retrieval rate of mature oocytes (mares: Ginther et al. 2007, Siddiqui et al. 2009a), fertilisation rate (women: Bhal et al. 1999, 2001) and pregnancy rate (women: Bhal et al. 1999, 2001, Coulam et al. 1999, Huey et al. 1999, Du et al. 2006, Shrestha et al. 2006, mares: Silva et al. 2006, heifers: Siddiqui et al. 2009b), and lower incidence of triploidy (women: Bhal et al. 2001). Studies on the relationship between blood-flow characteristics of the wall of the preovulatory follicle to oocyte retrieval and maturity have been done only in women and mares, and studies on fertilisation and embryo development of the oocyte after IVF have been done only in women.

In cattle, administration of $\mathrm{GnRH}$ initiates secretion of $\mathrm{LH}$ for 3-5 h (Thatcher et al. 1993), alters follicular development, and induces ovulation of the follicle (Thatcher et al. 1989, 1993, Macmillan \& Thatcher 1991). The role of LH in the antral follicle involves stimulation of the formation of the androgen substrate by the thecal cells; the androgen is converted to oestrogen by granulosa cells (Carruthers 1986). The LH surge before ovulation is responsible for the resumption of meiosis in the oocyte, activation of enzymes for follicle rupture, and stimulation of steriodogenesis, particularly, production of progesterone by the granulosa cells (Albertini et al. 1993). Insulin-like growth factor (IGF) 1 involves complex interactions among cumulus cells, gonadotrophins and steroids during oocyte maturation (Plancha \& Albertini 1994, Webb et al. 2007). IGF1 stimulates oestrogen production by granulosa cells during oocyte maturation. In the preovulatory follicle of mares, concentration of free IGF1 in the follicular fluid was greater in association with lower progesterone in follicular fluid, lower extent of blood flow in the follicular wall, less expansion of granulosa cells, and immaturity of the oocytes (Ginther et al. 2007). The preovulatory relationships of follicularfluid oestradiol, progesterone, and free IGF1 and systemic $\mathrm{LH}$, and oestradiol to competence of the oocyte for fertilisation and embryo development have not been reported in any species.

The present study tested the hypothesis of a positive relationship between the extent of in vivo vascular perfusion of the wall of the preovulatory follicle and the success of oocyte recovery and oocyte competence for IVF and embryo development in cattle. Greater vascular perfusion was based on a greater percentage of the follicular wall with colour Doppler signals of blood flow and lower spectral-Doppler pulsatility index (PI) and resistance index (RI) for a vessel of the wall (lower indices $=$ greater perfusion). In addition, the effects of systemic LH and oestradiol and follicular-fluid factors on fertilisation and embryo development were considered.

\section{Results \\ Oocyte and follicular fluid}

The actual diameter of the follicle when prostaglandin F2 $\alpha$ (PGF2 $\alpha$ ) was given (hour -36) was not different between groups for oocyte recovery versus non-recovery, cleavage versus non-cleavage, and embryo development to $>8$ cells versus $\leq 8$ cells (combined diameter, $11.7 \pm 0.1 \mathrm{~mm} ; n=61)$. Recovery of oocytes was attempted in 52 of 61 preovulatory follicles (one follicle per heifer). Nine follicles were removed from the experiment, owing to ovulation before hour 26 (hour of follicle aspiration; $n=6$ ) and rupture of the follicle during the aspiration procedure $(n=3)$. An oocyte was recovered in $79 \%(41 / 52)$ of the follicles (Table 1$)$. Differences that were significant (main effects and the interaction) or approached significance for the analyses of follicular diameter, percentage of the circumference of the follicular wall with blood-flow signals, and spectral Doppler indices ( $\mathrm{PI}$ and $\mathrm{RI}$ ) are presented (Fig. 1). For

Table 1 Relationship of granulosa cells and concentrations of follicular-fluid hormones to oocyte recovery, oocyte cleavage and embryo development $26 \mathrm{~h}$ after $\mathrm{GnRH}$ treatment when the preovulatory follicle was $\geq 11 \mathrm{~mm}$.

\begin{tabular}{|c|c|c|c|c|c|c|}
\hline \multirow[b]{2}{*}{ Characteristics } & \multicolumn{2}{|l|}{ Oocyte recovery } & \multicolumn{2}{|l|}{ Oocyte cleavage } & \multicolumn{2}{|c|}{ Embryo development } \\
\hline & Non-recovered & Recovered & Non-cleaved & Cleaved & $\leq 8$ cells & $>8$ cells \\
\hline Number of follicles & $11(21 \%)$ & $41(79 \%)$ & $8(21 \%)$ & $31(79 \%)$ & $14(45 \%)$ & $17(55 \%)$ \\
\hline \multicolumn{7}{|l|}{ Granulosa cells } \\
\hline Amount (score, 1-3) & $1.7 \pm 0.2^{\mathrm{a}}$ & $2.4 \pm 0.1^{b}$ & $2.4 \pm 0.2$ & $2.4 \pm 0.4$ & $2.4 \pm 0.1$ & $2.4 \pm 0.1$ \\
\hline Expansion (score, 1-3) & $2.2 \pm 0.2^{\mathrm{a}}$ & $2.8 \pm 0.1^{\mathrm{b}}$ & $2.9 \pm 0.1$ & $2.8 \pm 0.3$ & $2.9 \pm 0.1$ & $2.7 \pm 0.1$ \\
\hline \multicolumn{7}{|l|}{ Follicular-fluid hormones } \\
\hline Oestradiol $(\mathrm{ng} / \mathrm{ml})$ & $65.6 \pm 12.7$ & $61.2 \pm 3.1$ & $55.3 \pm 3.9$ & $60.8 \pm 20.2$ & $67.1 \pm 5.4^{\mathrm{a}}$ & $54.1 \pm 4.7^{\mathrm{b}}$ \\
\hline Progesterone $(\mathrm{ng} / \mathrm{ml})$ & $255 \pm 57$ & $203 \pm 17$ & $228 \pm 69$ & $197 \pm 76$ & $179 \pm 18$ & $217 \pm 22$ \\
\hline Free IGF1 (ng/ml) & $11.3 \pm 3.8^{\mathrm{a}}$ & $6.9 \pm 0.9^{b}$ & $13.6 \pm 3.0^{\mathrm{a}}$ & $5.0 \pm 0.6^{b}$ & $5.8 \pm 0.7^{\mathrm{a}}$ & $4.0 \pm 0.8^{b}$ \\
\hline
\end{tabular}

${ }^{\mathrm{a}, \mathrm{b}}$ Means with different letters within paired groups for each end point are different $(P<0.05$ to $P<0.001)$. 

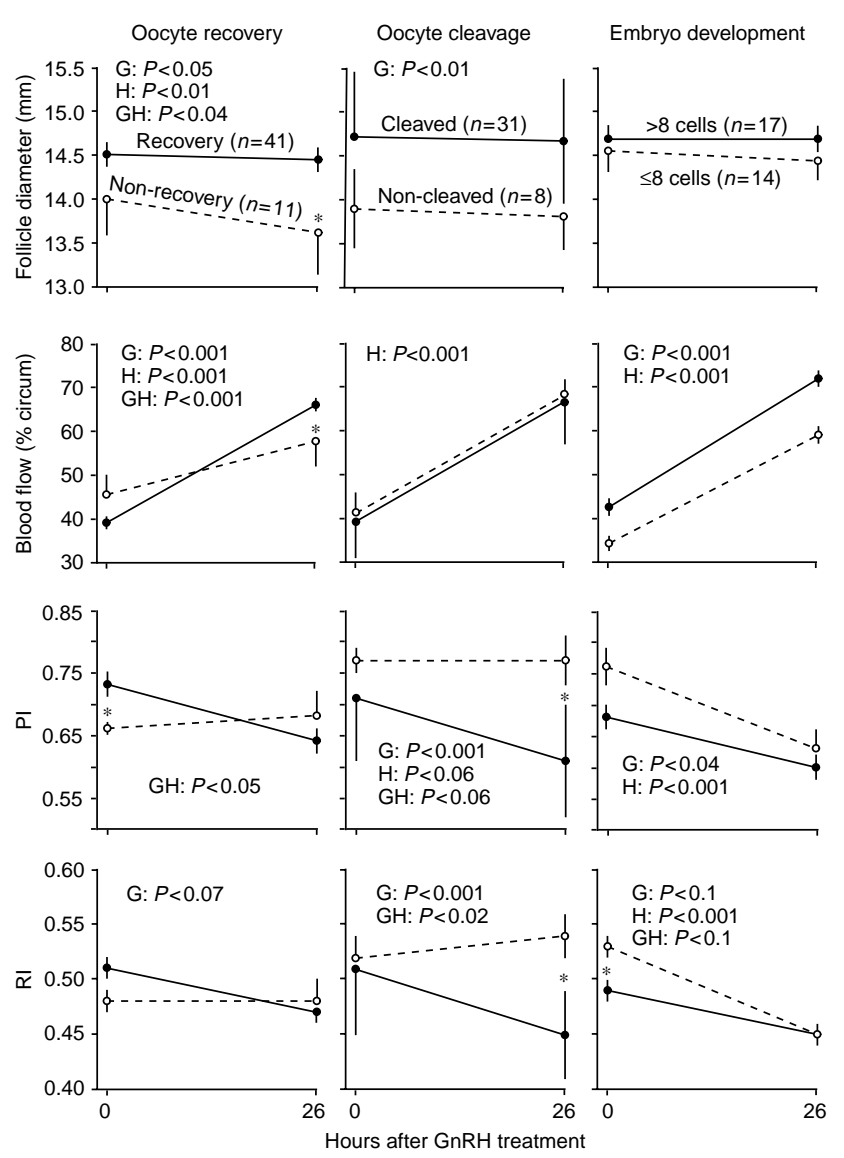

Figure 1 Mean ( \pm S.E.M.) for end points of the preovulatory follicle associated with oocyte recovery, oocyte cleavage and embryo development at hour 0 ( $\mathrm{GnRH}$ treatment) and hour 26 (oocyte recovery procedure). Blood flow $=$ percentage of follicle circumference with colour Doppler signals of blood flow, PI, pulsatility index and RI, resistance index. The indices ( $\mathrm{Pl}$ and $\mathrm{RI}$ ) are inversely related to the extent of tissue vascular perfusion downstream from the point of assessment at the most prominent colour spot in the follicle wall. Probabilities for significant main effects $(\mathrm{G}=$ group; $\mathrm{H}=$ hour $)$ and the interaction $(\mathrm{GH})$ are shown. An asterisk $\left(^{*}\right)$ indicates a statistical difference at hours 0 or 26 when a significant or approaching significant group-by-hour interaction was obtained.

oocyte recovery, both main effects (group and hour) and the interaction were significant for follicular diameter and percentage of follicular wall with blood-flow colour Doppler signals. The interactions primarily resulted from a greater $(P<0.05)$ diameter and greater $(P<0.05)$ percentage of follicular wall with blood-flow signals at hour 26 for the follicular group with oocyte recovery than with non-recovery. An interaction for PI resulted from a greater $(P<0.04)$ decrease in the index between hours 0 and 26 for follicles with oocyte recovery than with non-recovery. The difference between recovery and non-recovery approached significance for RI. No significant or approaching significant differences were found for blood velocity measurements (PSV, peak systolic velocity; EDV, end diastolic velocity; TAMV, time-averaged maximum velocity; data not shown).
At hour 26, the scores for amount and expansion of granulosa cells were greater for follicular fluid associated with oocyte recovery than with non-recovery $(P<0.05$; Table 1). Follicular-fluid concentration of free IGF1, but not oestradiol and progesterone, was less $(P<0.001)$ for follicles with oocyte recovery than with non-recovery.

\section{Oocyte cleavage}

A polar body was detected in each of the recovered oocytes $(n=41)$. The zona of two oocytes was broken during processing, and the oocytes were not used for the fertilisation procedure. The remaining 39 oocytes were inseminated, and cleavage occurred in 31 (79\%; Table 1). The results of the statistical analyses of follicular diameter, percentage of the circumference of follicular wall with blood-flow colour Doppler signals, and spectral Doppler indices (PI and RI) are shown for the non-cleaved and cleaved groups (Fig. 1). Greater follicular diameter was detected in the cleaved group, averaged over both hours (group effect), than in the noncleaved group. An increase in the percentage of the follicular wall with blood flow signals was obtained between hours 0 and 26 (hour effect), averaged over the two groups. Significant group effects were obtained for PI and $\mathrm{Rl}$, owing to lower indices in the cleaved group averaged over both hours. In addition, the group-by-hour interaction for $\mathrm{PI}$ approached significance and for RI was significant. The interactions represented a greater $(P<0.001)$ follicular wall vascular perfusion (lower indices) at hour 26 in the cleaved group than in the non-cleaved group. No significant difference was found for PSV. The EDV and TAMV were greater (group effects, $P<0.002$ and $P<0.02$ respectively) for the cleaved group $(4.8 \pm 0.1$ and $6.7 \pm 0.1 \mathrm{~cm} / \mathrm{s})$ than for the noncleaved group $(4.0 \pm 0.3$ and $6.0 \pm 0.3 \mathrm{~cm} / \mathrm{s})$. The scores for amount and expansion of granulosa cells and concentrations of oestradiol and progesterone in the follicular fluid were not different between non-cleaved and cleaved groups (Table 1). Free IGF1 concentration in follicular fluid was less $(P<0.001)$ in the cleaved group than in the non-cleaved group.

\section{Embryo development}

The percentage of embryos with $\leq 8$ cells and $>8$ cells was $45 \%$ and $55 \%$ respectively (Table 1 ). The results of the analyses of follicular diameter, percentage of the follicular wall with blood-flow colour Doppler signals and spectral Doppler indices (PI and RI) are presented (Fig. 1). No significant main effects or a group-by-hour interaction were obtained for follicular diameter between the two groups of embryos. The percentage of follicular wall with blood-flow signals was greater in the follicles that produced $>8$ cell embryos averaged over hours 0 and 26 (group effect) than for $\leq 8$ cell embryos. 
The percentage of wall with blood-flow signals increased between hours 0 and 26 averaged over the two groups (hour effect); there was no interaction of group-by-hour. Vascular perfusion in the follicular wall increased between hours 0 and 26 (hour effect) as indicated by a decrease in $\mathrm{PI}$ and $\mathrm{RI}$. The group effect was significant for $\mathrm{PI}$ and approached significance for RI, owing to greater vascular perfusion (lower indices) for the $>8$ cell embryos, averaged over hours 0 and 26. No significant main effects or interactions were obtained for PSV and TAMV. The main effect of hour was significant for EDV $(P<0.01)$, owing to greater velocity at hour 26 $(4.9 \pm 0.2 \mathrm{~cm} / \mathrm{s})$ than at hour $0(4.4 \pm 0.1 \mathrm{~cm} / \mathrm{s})$. The scores for the amount and expansion of the granulosa cells of the preovulatory follicle were not different between the two groups of embryos (Table 1). The concentration of follicular-fluid oestradiol and free IGF1 was less in the group of embryos with $>8$ cells than with $\leq 8$ cells. The concentration of follicular-fluid progesterone was not different between the groups.

\section{Plasma $\mathbf{L H}$ and oestradiol}

Plasma concentrations of $\mathrm{LH}$ and oestradiol decreased between hours 0 and 26 (significant main effect of hour) for each set of comparisons (oocyte recovery versus nonrecovery, oocyte cleavage versus non-cleavage, embryo development to $\leq 8$ cells versus $>8$ cells). However, there was no significant or approaching significant group effect for any set of oocyte/embryo comparisons and no interaction of group-by-hour (data not shown).

\section{Discussion}

The results supported the hypothesis that greater vascular perfusion of the preovulatory follicle was associated with greater success for each of the oocyte/embryo sets for oocyte recovery, oocyte cleavage and embryo development. The hypothesis was supported statistically for each set by a group effect averaged over hour 0 (hour of GnRH treatment) and hour 26 (hour of oocyte recovery) and/or by an interaction between group and hour. The interactions were attributable to greater vascular perfusion at either hour 0 or hour 26 in association with greater success for oocyte recovery and cleavage and embryo development. The positive effect of the extent of follicle vascularity on recovery of the oocyte was indicated by a greater increase in percentage of the follicular wall with colour Doppler signals of blood flow and by a decrease in spectral indices (decreased indices $=$ increased vascular perfusion) between hours 0 and 26 in the follicles with oocyte recovery than with non-recovery. The greater vascularity of the follicular wall in association with oocyte recovery is a novel finding in cattle and agrees with findings in women (Bhal et al. 2001, Du et al. 2006, Shrestha et al. 2006) and the tendency for a similar finding in mares (Ginther et al. 2007).

Preovulatory follicular vascular involvement in the subsequent in vitro cleavage of the recovered oocytes was indicated by the lower resistance indices (greater increase in vascular perfusion) at hour 26 than hour 0 (interaction) for a vessel of the follicular wall in the cleavage group. However, the percentage of blood-flow signals in the wall increased similarly between hours 0 and 26 in the cleaved and non-cleaved groups (no interaction). The reason for this apparent contradiction is unknown. Further support for greater vascular involvement in the wall of follicles that produced fertilisable oocytes, as indicated by successful cleavage, was the greater blood velocity (EDV and TAMV) for a vessel in the follicular wall in the cleavage group for both hours of assessment. The positive effect of the extent of vascular perfusion in the preovulatory follicle on the production of cleaved oocytes that developed beyond the eight-cell stage was indicated by greater percentage of blood-flow signals and greater vascular perfusion at both hours 0 and 26 in the $>8$ cell group. These findings indicated that the extent of vascularity of the preovulatory follicle had a positive carry-over effect on the ability of the oocyte to become fertilised and for the cleaved oocyte to develop beyond the eight-cell stage. These are novel findings in cattle. Development of cattle embryos beyond the eight-cell stage apparently is dependent on the inherent ability of the oocyte for genome activation (Memili \& First 2000). The present cleavage and embryo development results in heifers are compatible with a report in women that a greater frequency of pregnancy occurred after embryo transfer when the embryo was produced from an oocyte that was derived from a follicle with high-grade vascularity (Coulam et al. 1999).

Both greater percentage of blood-flow signals in the wall of the follicles and the decreased $\mathrm{PI}$ and $\mathrm{RI}$ in a vessel in the wall of the follicle indicate increased blood circulation (Ginther 2007) and presumably involved an increase in number and diameter of the arterioles that form a network encasing the follicle (Hunter 2003). The mechanisms for the effect of follicular vascularity on oocyte competence for fertilisation and embryo development are not known. It has been suggested that the competence of an oocyte for maturation, fertilisation and embryo viability after fertilisation mainly depends on the follicle (Moor et al. 1998, Webb et al. 2007). Greater blood flow in the follicle is related to the greater dissolved oxygen in the follicular fluid (Van Blerkom et al. 1997, Monteleone et al. 2008). The vascular system carries nutrients and oxygen to the follicle. Mitochondria play a vital role in the oocyte in providing ATP for activation at the time of fertilisation and for preimplantation embryo development (Dumollard et al. 2004). Speculatively, the association between reduced blood 
flow in the follicles and lower cleavage rate of the oocyte and less development of the embryo in the present study may have reflected reduced mitochondrial oxidative phosphorylation in the oocytes for ATP production. Further study is needed.

The similarity (no significant difference) in follicular diameter at hour 36 (hour of PGF treatment), and the significantly smaller diameter in the non-recovery and non-cleaved groups at hour 0 ( $\mathrm{GnRH}$ treatment) implies that the follicle grew at a slower rate after PGF treatment in the non-recovery and non-cleaved groups. The smaller preovulatory follicle at the time of $\mathrm{GnRH}$ treatment suggests that the ovulation-inducing treatment was given when the follicle was less developed. The association between greater follicular diameter and oocyte cleavage in the present study is in agreement with the previous reports of an association between greater follicular diameter and establishment of pregnancy in mares (Silva et al. 2006) and heifers (Perry et al. 2005, Siddiqui et al. 2009b). Although follicular diameter was not considered in the hypothesis, greater diameter was positively related to greater oocyte recovery and cleavage but not to embryo development beyond 8 cells. Greater follicular diameter would dictate greater follicular-fluid volume, which may have contributed to the greater oocyte-recovery rate. In addition, greater expansion of the granulosa cells and greater amount of granulosa cells also may have facilitated oocyte recovery. The association between less granulosa expansion and fewer granulosa cells in the non-recovery group also suggested that these follicles may have contained a high incidence of immature oocytes at the time of aspiration. The positive relationship between oocyte recovery and follicular diameter in the present study is consistent with a previous report in women (Bhal et al. 2001), but inconsistent with findings in mares (Ginther et al. 2007). In mares, non-recovery of the oocytes was associated with follicles of greater diameter and was attributed to greater immaturity of the follicle, as indicated by follicle echotexture and less expansion of granulosa cells.

In regard to the smaller follicular diameter in association with non-cleavage, the proportion of heifers that would have had a third follicular wave is not known. If the proportion was greater in the non-cleaved group than in the cleaved group, more follicles in the noncleaved group would have been in the static phase at $\geq 11 \mathrm{~mm}$ and would account for the subsequent slower mean growth rate and greater incidence of non-cleaved oocytes. Although this possibility cannot be discounted, the following observations are compatible with viability of the follicles in the non-cleaved group: 1) all individual follicles increased in diameter on the day before the follicle was $\geq 11 \mathrm{~mm}$ and between $\geq 11 \mathrm{~mm}$ and $\mathrm{GnRH}$ treatment, 2) there was no difference in follicular-fluid concentrations of oestradiol between the cleaved and non-cleaved groups on the day of aspiration, 3) all recovered oocytes were mature regardless of whether or not cleavage occurred and 4) the incidence of threewave oestrous cycles before the experimental oestrous cycle was low $(10 \%)$.

The greater follicular-fluid concentration of free IGF1 in the group with non-recovered oocytes and greater compactness of the granulosa cells are consistent with immaturity of the follicles. Greater concentrations of free IGF1 in the non-cleaved and the $\leq 8$ cell-embryo groups indicated on a temporal basis that greater free IGF1 concentration in the follicular fluid at hour 26 was associated with less competence of oocytes for cleavage and embryo development. These results agree with findings in women, wherein lower concentration of free IGF1 in the follicular fluid was associated with better embryo development (Wang et al. 2006). There was a temporal negative association at hour 26 between lower follicular-fluid concentration of free IGF1 and greater vascularity of the follicular wall. However, the role of IGF1 in follicle vascularisation apparently is unknown. These in vivo results for free IGF1 are inconsistent with a report (Oropeza et al. 2004) that intraovarian application of IGF1 improves the oocyte maturation rate, fertilisation rate, and extent of embryo development in cows. The reason for this apparent difference is unknown but indicates a need for further study.

In the previous studies in cattle (Acosta et al. 2003), rats (Varga et al. 1985), rabbits (Janson 1975) and sheep (Niswender et al. 1976), the role of oestradiol and LH on blood flow of the follicle wall was not well established. An increase of blood-flow velocity (TAMV) in the vessel of the follicular wall occurred $0.5 \mathrm{~h}$ after $\mathrm{GnRH}$ treatment, synchronously with an increase in systemic concentrations of oestradiol and LH (Acosta et al. 2003); follicular blood flow remained high, while systemic concentrations of oestradiol and $\mathrm{LH}$ returned to basal level by $6 \mathrm{~h}$ and remained low until ovulation. Further study is required with frequent blood sampling and Doppler ultrasographic scanning for a better understanding of the relationship of vascular perfusion in the preovulatory follicle and plasma oestradiol and $\mathrm{LH}$ concentrations between $\mathrm{GnRH}$ treatment and ovulation. The effect of follicular-fluid oestradiol or follicular vascular perfusion apparently is not known.

In conclusion, the study considered the effects of characteristics of the preovulatory follicle on oocyte retrieval and cleavage and on embryo development to $>8$ cells. Diameter of the follicle was greater for the oocyte-recovery group than for the non-recovery group and for the cleaved group than for non-cleaved group but was not associated with embryo development beyond eight cells. Based on Doppler ultrasonographic characteristics of the follicle, greater vascular perfusion of the follicular wall was associated with a greater rate of oocyte recovery and with a higher incidence of in vitro oocyte cleavage and embryo development of the retrieved oocytes. Lower concentrations of free 
IGF1 in follicular fluid were associated with a higher rate of oocyte recovery and cleavage and embryo development beyond eight cells.

\section{Materials and Methods}

\section{Animals}

Animals were handled in accordance with the United States Department of Agriculture Guide for Care and Use of Agricultural Animals in Research. Holstein heifers $(n=52)$ between 15-20 months of age and in good body condition were used. The heifers had regular oestrous cycles and no apparent abnormalities of the reproductive tract as determined by ultrasound examination (Ginther 1998). Ultrasound monitoring of the preovulatory follicle and the treatment procedures have been described (Siddiqui et al. 2009b). Briefly, the heifers were scanned daily by grey-scale (B-mode) ultrasonography beginning 12 days after ovulation until a $\geq 11 \mathrm{~mm}$ follicle of the second follicular wave was identified (mean, 15.0 \pm 0.3 days postovulation). Heifers received a luteolytic dose of PGF (25 mg per heifer, i.m.; dinoprost trimethamine, Lutalyse; Pfizer Animal Health, New York City, NY, USA) when the follicular diameter was $\geq 11 \mathrm{~mm}$ (hour -36 ). The PGF was given to assure that luteolysis occurred in all heifers before the $\mathrm{GnRH}$ treatment. The heifers were treated $36 \mathrm{~h}$ later (hour 0) with $\mathrm{GnRH}(100 \mu \mathrm{g}$ per heifer, i.m.; gonadorellin diacetate tetrahydrate, Ovacyst; Phoenix Scientific Inc., St. Joseph, MO, USA). Follicular diameter, follicular wall blood flow and blood samples for hormone assays were collected just before $\mathrm{GnRH}$ treatment (hour 0) and just before the oocyte-recovery procedure (hour 26). Oocyte recovery was attempted and follicular fluid was collected at hour 26.

\section{Ultrasonography}

Heifers were sedated with a sub-dose of xylazine hydrochloride (20 mg per animal, i.m; Xyla-Ject; Phoenix Pharmaceuticals Inc.) to minimise animal movement, as described for Doppler ultrasonic imaging (Araujo \& Ginther 2009). A duplex B-mode (grey-scale) and pulsed-wave colour Doppler ultrasound instrument (Aloka SSD-3500; Aloka America, Wallingford, CT, USA) equipped with a linear array $7.5 \mathrm{MHz}$ transducer (UST-5821-7.5) was used for transrectal scanning. For the grey-scale mode, the brightness and contrast controls of the monitor and the gain controls of the scanner were standardised to constant settings (Gastal et al. 2006). The procedure for Doppler ultrasonography of the preovulatory follicle of heifers has been described (Siddiqui et al. 2009b). Briefly, follicular diameter was obtained from an average of height and width of the antrum at the apparent maximal area from two frozen grey-scale images. The power-Doppler mode was used to display blood-flow signals from the vessels of the follicular wall. Percentage of follicular wall with colour Doppler signals was estimated while the entire follicle was being scanned in a slow continuous motion several times as described (Ginther 2007) at hour 0 (hour of GnRH treatment) and hour 26 (hour of follicle aspiration). The term 'circumference' refers to the periphery of a three-dimensional follicle. Colour Doppler images of relatively low and high vascularisation of preovulatory follicles are shown (Fig. 2A and D). The procedure for estimating the percentage of blood-flow signals has been used and validated by subsequent pixel analysis in the corpus luteum and follicles of heifers (Ginther et al. 2007, Araujo \& Ginther 2009). A comparable subjective procedure has been used for the preovulatory follicle of women (Chui
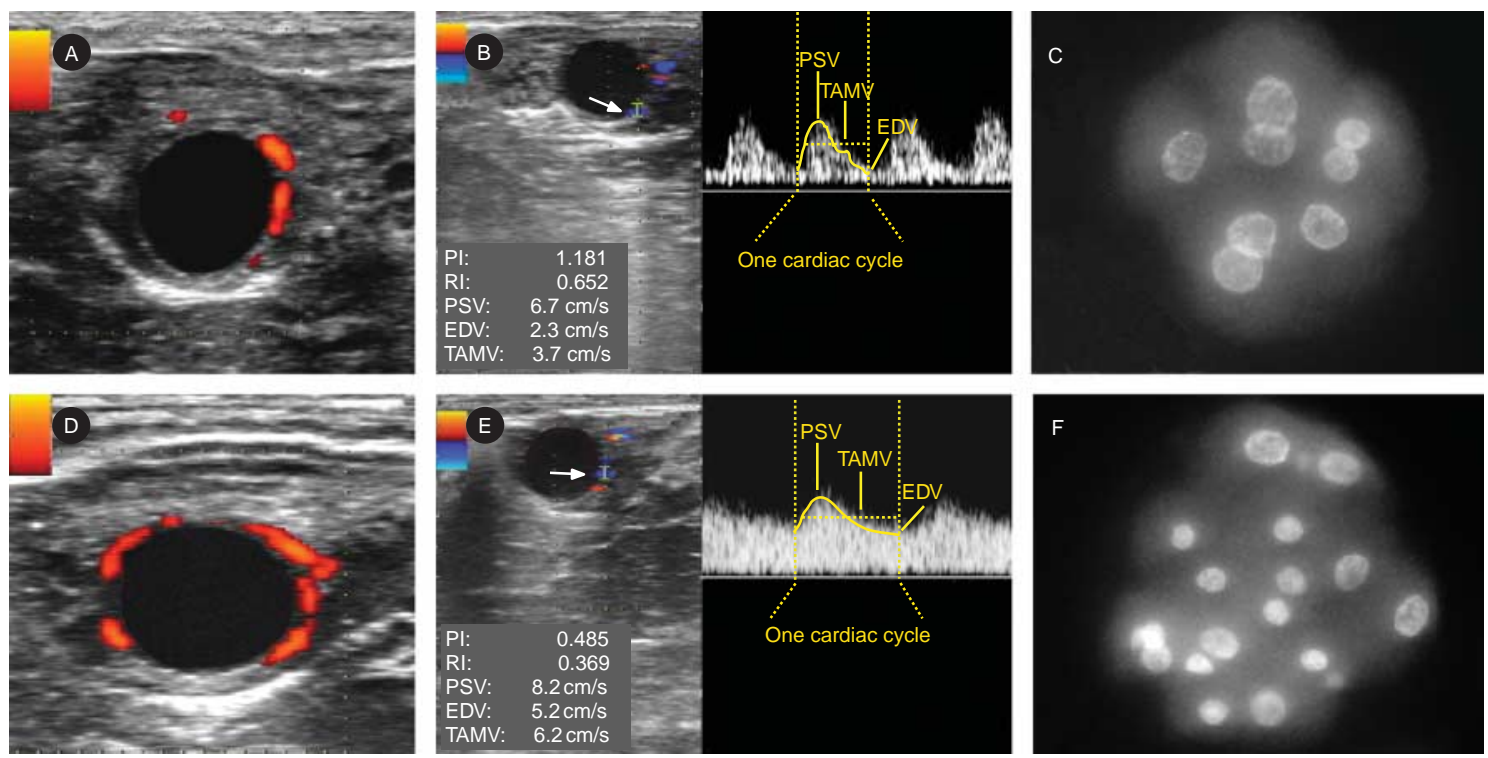

Figure 2 Representative Doppler ultrasonographic images of preovulatory follicles and embryos. The embryos were produced by IVF from the corresponding (left to right) follicle-derived oocytes. Power-Doppler ultrasonography displayed low (A) and high (D) percentage of the follicle wall with blood-flow signals at hour 26. The sample gate (white arrow) was placed on a colour spot in the wall of the preovulatory follicle to generate Doppler spectral graphs with low (B) and high (E) blood-flow velocities. The generated data in the lower-left corner of images B and E indicate the pulsatility index $(\mathrm{PI})$, resistance index (RI), peak systolic velocity (PSV), end diastolic velocity (EDV) and time-averaged maximum velocity (TAMV). Nuclei of an embryo with eight cells (C) and $>8$ cells (F) that were produced from the oocyte of follicles A and D respectively, are shown.

The embryos were stained with DNA fluorochrome to visualise the nuclei of the blastomeres $120 \mathrm{~h}$ after the oocyte was exposed to spermatozoa. 
et al. 1997, Miyazaki et al. 1998, Bhal et al. 2001), mares (Gastal et al. 2006, Silva et al. 2006, Ginther et al. 2007) and heifers (Siddiqui et al. 2009b).

For spectral Doppler assessment, the sample cursor or gate (width $=1 \mathrm{~mm}$ ) was set on the most prominent colour signal in the follicular wall (Fig. 2B and E). The angle of the ultrasound beam in relation to the direction of blood flow in the vessel (insonation angle) was unknown, and therefore, relative velocities for group comparisons, rather than actual velocities, were obtained (Ginther 2007). Doppler spectrums of three cardiac cycles were generated and one of the cycles was used for spectral measurements. The mean value of two measurements for each end point was used in the statistical analyses. The velocity end points from spectral Doppler ultrasonography of a vessel in the wall of the preovulatory follicle were PSV, EDV and TAMV. The end points for blood perfusion of the follicle wall were $\mathrm{PI}$ and $\mathrm{RI}$ and were computed from the velocity measurements by the scanner (Zwiebel \& Pellerito 2005). Doppler measurement techniques and other aspects of blood velocities and perfusion indices have been described previously (Zwiebel \& Pellerito 2005, Ginther 2007).

\section{Recovery of oocyte and follicular fluid}

Oocyte recovery and follicular fluid collection were done at hour 26 by transvaginal ultrasound-guided aspiration of follicular contents, using an 18-gauge single-lumen needle (length $55 \mathrm{~cm}$ ) and vacuum pump. The procedures for preparing the heifer, transrectal ovary positioning, transvaginal transducer placement and inserting the needle have been described previously (Ginther 1998). The aspirated follicular fluid and the flushing fluid (TL HEPES; Bioniche Animal Health Inc., Pullman, WA, USA) were held separately in two $10 \mathrm{ml}$ silicon coated sterile tubes (BD Vacutainer, cat \# 366430; Betcon Dikinson, Franklin Lakes, NJ, USA) in a $37{ }^{\circ} \mathrm{C}$ water bath until microscopic examination within $15 \mathrm{~min}$ after completion of the recovery procedure. The follicular fluid was searched under a stereomicroscope for an oocyte or cumulus oocyte complex (COC). If the oocyte or COC was not found in the follicular fluid, the flushing fluid was searched. After the search was completed, the follicular fluid was centrifuged (500 g, $10 \mathrm{~min}$ ) and 200-500 $\mu \mathrm{l}$ was stored at $-20{ }^{\circ} \mathrm{C}$ until assayed.

The granulosa cells were scored from 1 to 3 (minimal to maximal) for amount of cells and for the extent of expansion as described (Ginther et al. 2007). Extent of cell expansion was estimated as follows: score 1, tight or compact; score 2, mixture of compact and expanded; score 3, expanded with fluffy appearance. Characteristics of the preovulatory follicle and hormone concentrations were compared between oocyte nonrecovery and oocyte recovery groups.

\section{IVF and embryo development}

The identified oocyte or COCs were washed three times in TL HEPES and then treated with hyaluronidase $(0.05 \%)$ for $1 \mathrm{~min}$ to remove the cumulus. Each oocyte was fertilised and studied for embryo development in separate fertilisation drops to maintain oocyte identity as described previously (Fukui et al. 2000).
Briefly, drops $(10 \mu \mathrm{l})$ of fertilisation medium were made in a $35 \mathrm{~mm}$ Petri dish, covered with mineral oil, and equilibrated for $4 \mathrm{~h}$ at $39{ }^{\circ} \mathrm{C}$ in an environment of $5 \% \mathrm{CO}_{2}$ in humidified air of a $\mathrm{CO}_{2}$ incubator (HERAcell 150; Kendro Laboratory Products $\mathrm{GmbH}$, Langenselbold, Germany). The fertilisation medium was IVF-TL solution (EmbryoMax; Chemicon International, Phillipsburg, NJ, USA) and was supplemented with fatty acid free BSA $(6 \mathrm{mg} / \mathrm{ml})$, pyruvate $(0.2 \mathrm{mM})$, penicillamine $(20 \mathrm{mM})$, hypotaurine $(10 \mathrm{mM})$, epinephrine $(1 \mathrm{mM})$, and gentamicin $(50 \mu \mathrm{g} / \mathrm{ml})$. Semen used for fertilisation was from a single bull with proven fertility. Spermatozoa were separated from postthawed semen by the swim-up procedure and capacitated by heparin $(2 \mu \mathrm{g} / \mathrm{ml}$; Parrish et al. 1986). After washing, a cumulusfree oocyte was transferred into a fertilisation drop. The oocyte was fertilised by inseminating $10 \times 10^{3}$ spermatozoa into each fertilisation drop. After allowing $18 \mathrm{~h}$ for fertilisation, the oocyte or presumptive zygote was transferred into a drop of development medium. The development medium was Synthetic Oviductal fluid (SOF, EmbryoMax; Chemicon International) and was supplemented with fatty acid free BSA $(8 \mathrm{mg} / \mathrm{ml})$, pyruvate (0.2 mM), BME (essential amino acids, $50 \times, 10 \mu \mathrm{l} / \mathrm{ml})$, MEM (non-essential amino acids, $100 \times, 20 \mu \mathrm{l} / \mathrm{ml}$ ), and gentamicin $(50 \mu \mathrm{g} / \mathrm{ml})$ as described previously (Parrish et al. 1995). The oocyte was examined for indications of cleavage under a stereomicroscope $48 \mathrm{~h}$ after exposure to spermatozoa. Absence of cleavage after $48 \mathrm{~h}$ was used to define the oocyte as noncleaved and presumably included non-fertilisation and polyspermy. Characteristics of the preovulatory follicle and hormone concentrations were compared between the non-cleaved and cleaved groups.

The embryo was evaluated $120 \mathrm{~h}$ after exposure of the oocyte to spermatozoa by staining with DNA fluorochrome (Hoechst 33342, $10 \mu \mathrm{g} / \mathrm{ml}$ in PBS) and counting the nuclei (Fig. 2C and F) of the blastomeres under an epifluorescence microscope. The embryos were grouped as $\leq 8$ cells and $>8$ cells, based on in vitro blockage of bovine embryos at the eightcell stage (Memili \& First 2000). Blood flow and hormone concentrations of the preovulatory follicle were compared between the $\leq 8$ cell and $>8$ cell-embryo groups.

\section{Follicular-fluid and plasma hormone assays}

Blood samples were collected into heparinised tubes just before $\mathrm{GnRH}$ treatment (hour 0 ) and follicle aspiration (hour 26). Plasma concentration of oestradiol was determined by using a commercially available RIA kit (double antibody oestradiol; Diagnostic Products Corporation, Los Angeles, CA, USA) as described for heifers (Ginther et al. 2000), except for the following modifications. Standards $(0.78-100 \mathrm{pg} / \mathrm{ml})$ were prepared by serial dilution in steroid-free (charcoal extracted) bovine plasma. The standards and plasma samples $(500 \mu \mathrm{l})$ in duplicate were extracted simultaneously with $3 \mathrm{ml}$ of diethyl ether before assay. The ether was allowed to evaporate overnight, and the residue was dissolved in $100 \mu \mathrm{l}$ of RIA assay buffer (PBS with $0.1 \%$ gelatin). The kit-supplied primary antibody $(30 \mu \mathrm{l})$ and $\mathrm{I}^{125}$ labelled oestradiol $(75 \mu \mathrm{l})$ were added sequentially, vortexed, and incubated at room temperature for $2 \mathrm{~h}$ and $1 \mathrm{~h}$ respectively. The cold precipitating 
solution containing second antibody $(1 \mathrm{ml})$ was added to each assay tube, vortexed, and incubated for $20 \mathrm{~min}$ at room temperature. The tubes were centrifuged at $1700 \mathrm{~g}$ for $30 \mathrm{~min}$ and were decanted and counted in a $\gamma$-counter. Serial volumes of a pool of bovine oestrus plasma (500-200 $\mu \mathrm{l})$ were processed in the assay along with the experimental samples and resulted in a displacement curve that was similar to the standard curve. Plasma LH concentration was measured by RIA as described and validated in our laboratory (Adams et al. 1992), except that USDA-bLH-B-6 (National Hormone and Pituitary Program, Torrance, CA, USA) was used for iodination and reference standard, and USDA-309-684P was used as the primary antiserum. The intra-assay coefficient of variation (CV) and sensitivity for oestradiol and LH were $7.4 \%$ and $0.2 \mathrm{pg} / \mathrm{ml}$ and $10.37 \%$ and $0.10 \mathrm{ng} / \mathrm{ml}$ respectively. The concentrations of oestradiol, progesterone and free IGF1 in the follicular-fluid samples were assayed by radio- or enzyme-immunoassays, as described and validated in our laboratory (Beg et al. 2001). The intra-assay CV and sensitivity for follicular-fluid oestradiol, were $5.99 \%$ and $2.0 \mathrm{pg} / \mathrm{ml}$ respectively. For progesterone and free IGF1 in the follicular fluid, the intra- and inter-assay CV and sensitivity were $2.5 \%, 11.06 \%$, and $0.05 \mathrm{ng} / \mathrm{ml}$ and $2.6 \%$, $13.5 \%$, and $0.01 \mathrm{ng} / \mathrm{ml}$ respectively.

\section{Statistical analyses}

Blood-flow measurements and plasma hormone concentrations during pre-ovulation were compared within each of the three sets of oocyte/embryo groups (non-recovered versus recovered groups, non-cleaved versus cleaved groups, and $\leq 8$ cell versus $>8$ cell groups). Quantitative data were analysed by SAS MIXED PROCEDURE to determine the main effects of group and hour and their interactions, using a repeated statement to account for the autocorrelation between measurements (version 9.1.3; SAS Institute Inc., Cary, NC, USA). Quantitative end points for hour 26 were analysed between groups and within each set by unpaired Student's $t$-tests. A probability of $P \leq 0.05$ indicated that a difference was significant and a probability between $P>0.05$ and $<0.1$ indicated that significance was approached. Data are presented as the mean \pm s.E.M., unless otherwise indicated.

\section{Declaration of interest}

The authors declare that there is no conflict of interest that would prejudice the impartiality of this scientific work.

\section{Funding}

The study was supported by Eutheria Foundation (Project H2-AZ-08).

\section{Acknowledgements}

The authors acknowledge donations of semen straws from Alta Genetics Inc., Watertown, WI, USA and Lutalyse from Pfizer Animal Health, New York City, NY, USA. The authors thank
Dr John Parrish, Professor, Department of Animal Sciences, University of Wisconsin-Madison, WI for the use of a fluorescence microscope and for technical advice on IVF.

\section{References}

Acosta TJ, Hayashi KG, Ohtani M \& Miyamoto A 2003 Local changes in blood flow within the preovulatory follicle wall and early corpus luteum in cows. Reproduction 125 759-767.

Adams GP, Matteri RL, Kastelic JP, Ko JCH \& Ginther OJ 1992 Association between surges of follicle-stimulating hormone and the emergence of follicular waves in heifers. Journal of Reproduction and Fertility $\mathbf{9 4}$ 177-188.

Albertini DF, Wickramasinghe D, Messinger S, Mattson BA \& Plancha CE 1993 Nuclear and cytoplasmic changes during oocyte maturation. In Preimplantation Embryo Development, pp 3-21. Ed. BD Bavister. New York: Springer-Verlag.

Araujo RR \& Ginther OJ 2009 Vascular perfusion of the reproductive organs in mares and heifers during sedation by detomidine and xylazine. American Journal of Veterinary Research 70 141-148

Beg MA, Bergfelt DR, Kot K, Wiltbank MC \& Ginther OJ 2001 Follicularfluid factors and granulosa-cell gene expression associated with follicle deviation in cattle. Biology of Reproduction 64 4324-4341.

Bhal PS, Pugh ND, Chui DK, Gregory L, Walker SM \& Shaw RW 1999 The use of transvaginal power Doppler ultrasonography to evaluate the relationship between perifollicular vascularity and outcome in in vitro fertilization treatment cycles. Human Reproduction 14 939-945.

Bhal PS, Pugh ND, Gregory L, O'Brien SO \& Shaw RW 2001 Perifollicular vascularity as a potential variable affecting outcome in stimulated intrauterine insemination treatment cycles: a study using transvaginal power Doppler. Human Reproduction 16 1682-1689.

Van Blerkom J, Antczak M \& Schrader R 1997 The development potential of the human oocyte is related to the dissolved oxygen content of follicular fluid: association with vascular endothelial growth factor levels and perifollicular blood flow characteristics. Human Reproduction 12 1047-1055.

Carruthers TD 1986 Principles of hormone therapy in theriogenology. In Current Therapy in Theriogenology, pp 3-13. Ed. DA Morrow. Philadelphia: WB Saunders Company.

Chui DK, Pugh ND, Walker SM, Gregory L \& Shaw RW 1997 Follicular vascularity - the predictive value of transvaginal power Doppler ultrasonography in an in vitro fertilization programme: a preliminary study. Human Reproduction 12 191-196.

Coulam CB, Goodman C \& Rinehart JS 1999 Colour Doppler indices of follicular blood flow as predictors of pregnancy after in vitro fertilization and embryo transfer. Human Reproduction 14 1979-1982.

Du B, Takahashi K, Ishida GM, Nakahara K, Saito H \& Kurachi H 2006 Usefulness of intraovarian artery pulsatility and resistance indices measurement on the day of follicle aspiration for the assessment of oocyte quality. Fertility and Sterility 85 366-370.

Dumollard R, Marangos P, Fitzharris G, Swann K, Duchen M \& Carrol J 2004 Sperm-triggered $\left[\mathrm{Ca}^{2+}\right.$ ] oscillations on $\mathrm{Ca}^{2+}$ homeostasis in the mouse egg have an absolute requirement for mitochondrial ATP production. Development 131 3057-3067.

Fleischer AC 1991 Ultrasound imaging - 2000: assessment of utero-ovarian blood flow with transvaginal color Doppler sonography; potential clinical application in infertility. Fertility and Sterility 55 684-691.

Fukui Y, Kikuchi Y, Kondo H \& Mizushima S 2000 Fertilizability and developmental capacity of individually cultured bovine oocytes. Theriogenology 53 1553-1565.

Gastal EL, Gastal MO \& Ginther OJ 2006 Relationships of changes in B-mode echotexture and colour-Doppler signals in the wall of the preovulatory follicle to changes in systemic oestradiol concentrations and the effects of human chorionic gonadotrophin in mares. Reproduction 131 699-709.

Ginther OJ 1998 Follilces. In Ultrasonic Imaging and Animal Reproduction: Cattle: Book 3, pp 29-58. Cross Plains: Equiservices Publishing.

Ginther OJ 2007 Producing color-flow images. In Ultrasonic Imaging and Animal Reproduction: Color-Doppler Ultrasonography, Book 4, pp 39-60. Cross Plains: Equiservices Publishing. 
Ginther OJ \& Utt MD 2004 Doppler ultrasound in equine reproduction: principles, techniques and potential. Journal of Equine Veterinary Science 24 516-526.

Ginther OJ, Bergfelt DR, Kulick LJ \& Kot K 2000 Selection of the dominant follicle in cattle: role of two-way functional coupling between folliclestimulating hormone and the follicles. Biology of Reproduction $\mathbf{6 2}$ 920-927.

Ginther OJ, Gastal EL, Gastal MO, Siddiqui MAR \& Beg MA 2007 Relationship of follicle versus oocyte maturity to ultrasound morphology, blood flow and hormone concentrations of the preovulatory follicle in mares. Biology of Reproduction 77 202-208.

Herzog K \& Bollwein H 2007 Application of Doppler ultrasonography in cattle reproduction. Reproduction in Domestic Animals 42 51-58.

Huey S, Abuhamad A, Barroso G, Hsu MI, Kolm P, Mayer I \& Oehninger S 1999 Perifollicular blood flow Doppler indices, but not follicular pO2, pCO2, or $\mathrm{pH}$, predict oocyte developmental competence in in vitro fertilization. Fertility and Sterility 72 707-712.

Hunter RHF 2003 Physiology of the ovaries and maturing Graafian follicles. In Physiology of the Graafian Follicle and Ovulation, pp 57-88. Cambridge: Cambridge University Press.

Janson PO 1975 Effects of luteinizing hormone on blood flow in the follicular rabbit ovary, as measured by radioactive microspheres. Acta Endocrinologica 79 122-133.

Macmillan KL \& Thatcher WW 1991 Effects of an agonist of gonadotropinreleasing hormone on ovarian follicles in cattle. Biology of Reproduction 45 883-889.

Memili E \& First NL 2000 Zygotic and embryonic gene expression in cow: a review of timing and mechanisms of early gene expression as compared with other species. Zygote 8 87-96.

Miyamoto A, Shirasuna K, Hayashi KG, Kamada D, Awashima C, Kaneko E, Acosta TJ \& Matsui M 2006 A potential use of color ultrasound as a tool for reproductive management: new observations using color ultrasound scanning that were not possible with imaging only in black and white. Journal of Reproduction and Development 52 153-160.

Miyazaki T, Tanaka M, Miyakoshi K, Minegishi K, Kasai K \& Yoshimura Y 1998 Power and color Doppler ultrasonography for the evaluation of the vasculature of the human corpus luteum. Human Reproduction $\mathbf{1 3}$ 2836-2841.

Monteleone P, Giovanni Artini P, Simi G, Casarosa E, Cela V \& Genazzani AR 2008 Follicular fluid VEGF levels directly correlate with perifollicular blood flow in normoresponder patients undergoing IVF. Journal of Assisted Reproduction and Genetics 25 183-186.

Moor RM, Dai Y, Lee C \& Fulka J Jr 1998 Oocyte maturation and embryonic failure. Human Reproduction Update 4 223-236.

Ng EH, Tang OS, Chan CC \& Ho PC 2006 Ovarian stromal vascularity is not predictive of ovarian response and pregnancy. Reproductive Biomedicine Online 12 43-49.

Niswender GD, Reimers TJ, Diekman MA \& Nett TM 1976 Blood flow: a mediator of ovarian function. Biology of Reproduction 14 64-81.

Oropeza A, Wrenzycki C, Herrmann D, Hadeler KG \& Niemann H 2004 Improvement of the developmental capacity of oocytes from prepubertal cattle by intraovarian insulin-like growth factor-I application. Biology of Reproduction 70 1634-1643.

Parrish JJ, Susko-Parrish JL, Leibfried-Rutledge ML, Critser ES, Eyestone WH \& First NL 1986 Bovine in vitro fertilization with frozen-thawed semen. Theriogenology 25 591-600.
Parrish JJ, Krogenaes A \& Susko-Parrish JL 1995 Effect of bovine sperm separation by either swim-up or Percoll method on success of in vitro fertilization and early embryonic development. Theriogenology $\mathbf{4 4}$ 859-869.

Perry GA, Smith MF, Lucy MC, Green JA, Parks TE, MacNeil MD, Roberts AJ \& Geary TW 2005 Relationship between follicle size at insemination and pregnancy success. PNAS 102 5268-5273.

Plancha EC \& Albertini DF 1994 Hormonal regulation of meiotic maturation in the hamster oocyte involves a cytoskeleton-mediated process. Biology of Reproduction 51 852-864.

Ragni G, Anselmino M, Nicolosi AE, Brambilla ME, Calanna G \& Somigliana E 2007 Follicular vascularity is not predictive of pregnancy outcome in mild controlled ovarian stimulation and IUI cycles. Human Reproduction 22 210-214.

Shrestha SM, Costello MF, Sjoblom P, McNally G, Bennett M, Steigrad SJ \& Hughes GJ 2006 Power Doppler ultrasound assessment of follicular vascularity in the early follicular phase and its relationship with outcome of in vitro fertilization. Journal of Assisted Reproduction and Genetics 23 161-169.

Siddiqui MAR, Gastal EL, Gastal MO, Beg MA \& Ginther OJ 2009a Effect of hCG in the presence of hCG antibodies on the follicle, hormone concentrations, and the oocyte in mares. Reproduction in Domestic Animals [in press].

Siddiqui MAR, Almamun M \& Ginther OJ 2009b Blood flow in the wall of the preovulatory follicle and its relationship to pregnancy establishment in heifers. Animal Reproduction Science [in press] DOI: 10.1016/j.anireprosci.2008.07.008.

Silva LA, Gastal EL, Gastal MO, Beg MA \& Ginther OJ 2006 Relationship between vascularity of the preovulatory follicle and establishment of pregnancy in mares. Animal Reproduction $3339-346$.

Thatcher WW, Macmillan KL, Hansen PJ \& Drost M 1989 Concepts for the regulation of corpus luteum function by the conceptus and ovarian follicles to improve fertility. Theriogenology 31 149-164.

Thatcher WW, Drost M, Savio JD, Macmillan KL, Entwistle KW, Schmitt EJ, De la Sota RL \& Morris GR 1993 New clinical uses of GnRH and its analogues in cattle. Animal Reproduction Science 3327.

Varga B, Horvath E, Follyy G \& Stark E 1985 Study of the luteinizing hormone-induced increase of ovarian blood flow during the estrous cycle in the rat. Biology of Reproduction 32 480-488.

Wang TH, Chang CL, Wu HM, Chiu YM, Chen CK \& Wang HS 2006 Insulinlike growth factor-II (IGF-II), IGF-binding protein-3 (IGFBP-3), and IGFBP-4 in follicular fluid are associated with oocyte maturation and embryo development. Fertility and Sterility 86 1392-1401.

Webb R, Garnsworthy PC, Campbell BK \& Hunter MG 2007 Intra-ovarian regulation of follicular development and oocyte competence in farm animals. Theriogenology 685 S22-S29.

Zwiebel WJ \& Pellerito JS 2005 Basic concepts of Doppler frequency spectrum analysis and ultrasound blood flow imaging. In Introduction to Vascular Ultrasonography, pp 46-48. Eds WJ Zwiebel \& JS Pellerito. Phildelphia: Elsevier Saunders.

Received 23 September 2008

First decision 9 December 2008

Accepted 27 January 2009 